Original Research Paper

\title{
Protective Role of Chichorium intybus Extract Against Renal Toxicity Induced by Magnetite Silver Nanoparticles in Male Rats
}

\author{
${ }^{1}$ Doha M. Beltagy, ${ }^{2}$ Ehab Tousson, ${ }^{3}$ Nabiha I Abdo and ${ }^{1}$ Batoul M. Izzularab \\ ${ }^{1}$ Department of Biochemistry Division, Chemistry, Faculty of Science, Damanhour University, Egypt \\ ${ }^{2}$ Department of Zoology, Faculty of Science, Tanta University, Egypt \\ ${ }^{3}$ Department of Basic Sciences, Higher Institute of Engineering and Technology, New Borg El-Arab City, Egypt
}

\author{
Article history \\ Received: 02-01-2021 \\ Revised: 17-05-2021 \\ Accepted: 26-07-2021 \\ Corresponding author: \\ Doha M. Beltagy \\ Biochemistry Division, \\ Chemistry Department, Faculty \\ of Science, Damanhour \\ University, Egypt \\ E-mail: dohabel4@yahoo.com
}

\begin{abstract}
Magnetite silver nanoparticles $\left(\mathrm{Fe}_{3} \mathrm{O}_{4} / \mathrm{AgNPs}\right)$ symbolize a new candidate in several industrial and biological products for their activities, simple preparation and low synthesis costs. Many studies recommended the usage of $\mathrm{Fe}_{3} \mathrm{O}_{4} / \mathrm{AgNPs}$ to overcome lacking biocompatibility of AgNPs inside the body. However, $\mathrm{Fe}_{3} \mathrm{O}_{4} / \mathrm{AgNPs}$ also has toxic effects on kidney tissues. In this study, AgNPs was synthesized on the surface of magnetic nanoparticles $\left(\mathrm{Fe}_{3} \mathrm{O}_{4}\right)$ as a core-shell hetero-structure and used to induce renal injury. The microstructure, morphology and magnetic properties of $\mathrm{Fe}_{3} \mathrm{O}_{4} / \mathrm{AgNPs}$ were characterized using different analysis as X-ray diffraction, scanning electron microscopy and vibrating sample magnetometry. This study aimed to evaluate the protective effects of chicory (Chichorium intybus) fruit extract against kidney injury induced by $\mathrm{Fe}_{3} \mathrm{O}_{4} / \mathrm{AgNPs}$ administration in rats. The study was carried out on 40 male adult Sprague Dawley rats (12 weeks old, 140-145 g). Rats were randomly classified into four groups. Group-1 included control rats; group- 2 contained the administered chicory extract rats; group-3 was the rats injected withFe $\mathrm{O}_{4} / \mathrm{AgNPs}$; and group-4-in which rats administered with $\mathrm{Fe}_{3} \mathrm{O}_{4} / \mathrm{AgNPs}$ then treated by chicory extract. The obtained results showed that kidney function tests as urea and creatinine increased by about 1.5 folds in rats injected with $\mathrm{Fe}_{3} \mathrm{O}_{4} / \mathrm{AgNPs}$ (G3). Malondialdehyde (MDA) concentrations in kidney tissue duplicated and serum potassium levels increased by about 1.2 folds, while serum sodium and calcium ions slightly decreased in G3. On the other hand, reduced glutathione declined in G3 to nearly one-half normal values in G1. Superoxide dismutase and catalase enzymes decreased to about 0.7 folds in G3. Chicory extract administration in G4 improved all these parameters to nearly their normal values. In conclusion, the obtained results in the current study indicated the protective effects of chicory extract against kidney injury and oxidative stress induced by $\mathrm{Fe}_{3} \mathrm{O}_{4} / \mathrm{AgNPs}$.
\end{abstract}

Keywords: Nanoparticles, Chicory, Kidney, Oxidative Stress, TNF $\alpha$, P53

\section{Introduction}

With the immense spread of nanoparticles (NPs, ranged from 1-100 $\mathrm{nm}$ ) in industry and purchaser markets, the increased accumulation of nanomaterials in the environment and human exposure to NPs grew to be fact (Yousef et al., 2019). Silver nanoparticles (AgNPs) can be considered the most largely related nanomaterial in the medicinal and biochemical fields, which leads to take care about security restricts and the danger related to dissociate producing active $\mathrm{Ag}^{+}$into the human body. Assessments of AgNP toxicity are restricted and limited to only in vitro studies of its cytotoxicity and genotoxicity properties against different cell lines and tissue cultures (Hassanen et al., 2019; Altwaijry et al., 2021). All in vivo studies indicated that AgNPs transferred through blood stream once after absorption regardless the route of application. Inside the body, AgNPs can easily accumulate in several organelles and give rise to many pathological change such as hepatic dysfunction, renal injury and brain damage (Barbir et al., 
2019). In order to try to overcome this limitation and improve its properties, many previous studies tried to use Magnetite silver nanoparticles $\left(\mathrm{Fe}_{3} \mathrm{O}_{4} / \mathrm{AgNPs}\right)$ which symbolized a promising candidate for their amazing biocidal activity, simple preparation and low production costs. However, it also still has toxic effects on kidney tissues (Hosu et al., 2019; Ivashchenko et al., 2015).

Acute Kidney Injury (AKI) can lead to nephron injuries which in turn, can lead to death. The major sign of AKI is the great decrease in Glomerular Filtration Rate (GFR) due to renal blood flow reduction. Inflammation is an important reason of AKI leading to extensive stage of injury, with losing sensitivity to the vasodilator therapy (Basile et al., 2012). The usage of traditional and alternative medicine has been recently increased. The antioxidant impacts of different plant extracts play important roles in several diseases treatment (Tousson et al., 2018; Mutar et al., 2020). The ancient Egyptians planted Cichorium intybus Linn to be used as a medicinal plant. It was used because of its many advisable outcomes as hepatoprotective, neuroprotective, hypolipidemic, antioxidant and anti-inflammatory activities (Keshk et al., 2019). Chemical analysis of the fresh chicory revealed that typically it composed of mainly inulin and sucrose (68 and 14\%, respectively), other components as protein, cellulose and ash present small amounts. On the other hand, dried chicory composed approximately of $98 \%$ inulin (Hassan and Yousef, 2010).

The current study purposed to synthesize and characterize magnetite $\left(\mathrm{Fe}_{3} \mathrm{O}_{4}\right)_{\text {core }}-(\mathrm{Ag})_{\text {shell }}$ nanoparticles and examine its toxic effect on kidney in rats. The study also aimed to evaluate the protective effects of chicory (Chichorium intybus) fruit extract against kidney injury induced by $\mathrm{Fe}_{3} \mathrm{O}_{4} / \mathrm{AgNPs}$ administration in rats.

\section{Materials and Methods}

All required chemicals as ferric chloride $\left(\mathrm{FeCl}_{3} \cdot 6 \mathrm{H}_{2} \mathrm{O}\right)$, ferrous sulphate $\left(\mathrm{FeSO}_{4} \cdot 6 \mathrm{H}_{2} \mathrm{O}\right)$, ammonia, silver nitrate and glucose were obtained with high purity degree from Sigma-Aldrich

\section{Synthesis of Magnetite $\left(\mathrm{Fe}_{3} \mathrm{O}_{4}\right)_{\text {core }}-\mathrm{Ag}_{\text {shell }}$ Nanoparticles}

Magnetite nanoparticles $\left(\mathrm{Fe}_{3} \mathrm{O}_{4}\right)$ had been prepared using the coprecipitation method as reported previously (Abdo et al., 2019). $\mathrm{Fe}_{3} \mathrm{O}_{4}$ nanoparticles were each coated using the noble metal silver (Ag). To coat the magnetite particles $\left(\mathrm{Fe}_{3} \mathrm{O}_{4}\right)$ with silver, $0.5 \mathrm{~g}$ of glucose was added to $\mathrm{Fe}_{3} \mathrm{O}_{4}$ and silver nitrate with a molar ratio of $1: 0.5$. Then, mixture was sonicated for about $15 \mathrm{~min}$ and incubated in a hot water bath with a slow stirring for $1 \mathrm{~h}$. As the particles are gradually coated by silver, the black $\mathrm{Fe}_{3} \mathrm{O}_{4}$ particles converted gradually into a brownish color. After a while, the brown mass was precipitated at the bottom of the flask. After cooling to room temperature, it was centrifuged and the brownish precipitate was washed several times with water and then dried at $60^{\circ} \mathrm{C}$.

\section{Characterization of the Synthesized $\mathrm{Fe}_{3} \mathrm{O}_{4} / \mathrm{AgNPS}$}

The synthesized particles were characterized by Scanning Electron Microscopy (SEM), X-Ray Diffraction pattern (XRD) and Vibrating Sample Magnetometer (VSM).

The morphology of $\mathrm{Fe}_{3} \mathrm{O}_{4}-\mathrm{Ag}$ nanoparticles were analyzed using Scanning Electron Microscopy (JEOL SEM, JSM-636OLA, Japan) at an accelerated voltage $20 \mathrm{kV}$.

XRD measurements were recorded on (Shimadzu LabX XRD-6100 X-ray diffractometer, Japan). That was operated at a voltage of $40 \mathrm{kV}$ and a current of $30 \mathrm{~mA}$ with an excitation source of CuK $\alpha$ radiation $(\lambda=1.541 \AA)$, in the range of scanning angle 30 to $80^{\circ}$ at a scan rate of $5 \%$ min with the step width $0.02^{\circ}$. For XRD measurements, $\mathrm{Fe}_{3} \mathrm{O}_{4}-\mathrm{Ag}$ nanoparticles data obtained as powder samples.

Magnetic characteristics were measured by VSM (Lake Shore-7410 vibrating sample magnetometer, USA), magnetic field up to 30000 Oe. Parameters like specific saturation Magnetization (Ms), coercivity (Hc) and retentivity (remanence $\mathrm{Mr}$ ) were evaluated.

The average size of $\mathrm{Fe}_{3} \mathrm{O}_{4}-\mathrm{Ag}$ NPs calculated by applying Debye-Scherrer equation (Malapati et al., 2018), which gives a relationship between peak broadening in $\mathrm{XRD}$ and particle size that is demonstrated by following equation: $D=k \lambda /(\beta \cdot \cos \theta)$, where $D$ is the particle size of the crystal, $\mathrm{k}$ is Scherrer constant (0.9), $\lambda$ is the X-ray wavelength $(0.154 \mathrm{~nm}), \beta$ is the width of the XRD peak at half-height (FWHM) and $\theta$ is the Bragg diffraction angle for calculating d-spacing from Bragg`s law as; d $=\mathrm{n} \lambda / 2 \sin \theta$. The lattice constant (a) of the cubic crystal was computed using the $\mathrm{d}$-spacing values and the respective (hkl) parameters as; $a=d^{*} \sqrt{ }\left(h^{2}+k^{2}+l^{2}\right)$.

\section{Extraction of Chicory}

The fruits of chicory (Chichorium intybus Linn, edible herb growing wildly in Egypt among many other plants, blooming in late spring till mid-fall) were collected from the Agricultural Research Center, Giza, Egypt.

The extraction assay followed the hydro-alcoholic extract protocol as previously described (Saggu et al., 2014). Exactly 100 gram of Chicory fruits were immersed in one liter of methanol for $8 \mathrm{~h}$ or overnight at room temperature, after that it filtered to obtain the methanolic crude extract. One liter of methanol was added to the sample residue and heated to reach boiling and refluxed in a water bath for at least $2 \mathrm{~h}$. Filtration process was repeated and the filtrate was added to the previously obtained methanolic crude extract. By a similar method, all the previous steps were repeated but by using distilled water (instead of methanol). The watery filtrate was collected to the methanolic extract to achieve the final hydro-alcoholic 
crude extract. This hydro-alcoholic crude extract was evaporated and dried in reduced pressure conditions at $60^{\circ} \mathrm{C}$ and then it stored in dark bottles and frozen till using.

\section{In Vivo Study}

Adult Sprague Dawley rats (40 male, 12 weeks old, 140-145 g) were obtained from the Egyptian Organization for Biological Products and Vaccines in Cairo and fed on the standard rodent diet (Egyptian Company of Oils and Soap Kafr-El Zayat Egypt) and water available ad libitum. The study was carried out according to the ethical protocol of Institutional Animal Care and Use Committee of Faculty of Science, Tanta University, code No. IACUC-SCI-TU-00125.

\section{Animal Treatments}

The rats were acclimatized for only one week in the animal house and then they were randomly divided into four groups (10 rats for each):

Group 1 (control): Rats did not receive any treatment and served as control.

Group 2 (Chicory): Rats were administered with only the chicory extract ( $100 \mathrm{mg} / \mathrm{kg} \mathrm{BW} /$ daily) by oral gavage for successive four weeks (Saggu et al., 2014).

Group $3\left(\mathrm{Fe}_{3} \mathrm{O}_{4} / \mathrm{AgNPs}\right.$ twice a week): Rats were intraperitoneally injected with magnetite silver nanoparticles $\left(\mathrm{Fe}_{3} \mathrm{O}_{4} / \mathrm{AgNPs}\right)(100 \mathrm{mg} / \mathrm{kg} \mathrm{BW})$ twice a week for eight successive weeks (Altwaijry et al., 2020).

Group 4 ( $\mathrm{Fe}_{3} \mathrm{O}_{4} / \mathrm{AgNPs}^{+}$Chicory): Rats were injected with silver nanoparticles $(100 \mathrm{mg} / \mathrm{kg} \mathrm{BW} /$ twice a week) for eight weeks and then treated with chicory extract (100 mg/kg b.wt/daily) for another four weeks.

\section{Blood and Tissue Homogenate Preparation}

After consummation of the experiment strategy, rats were fasted for $10 \mathrm{~h}$ and were euthanized with intraperitoneal infusion of sodium pentobarbital and exposed to a total necropsy. Blood samples of each rat were gathered from sub-par vena cava and collected in non-heparinized tubes and left for 20-30 min. Then, it was centrifuged at $5000 \mathrm{rpm}$ for $10 \mathrm{~min}$ to isolate the sera which were stored as aliquots at $-80^{\circ} \mathrm{C}$ until required.

Kidneys were carefully removed from rats, then washed with ice-cold saline three times then chilled on ice, divided into four sections, one part were fixed in $10 \%$ neutral buffered formalin that used for histological and immunohistological investigations (Tousson et al., 2016). The rest of organs kept in aluminum foil and stored at $-80^{\circ} \mathrm{C}$ until tissue homogenization at required.

Kidney tissues were prepared for determination of antioxidant parameters. To evacuate any red blood cells and clots from tissues, they were washed with a mixed solution of Phosphate Buffered Saline (PBS) pH 7.4 and $0.16 \mathrm{mg} / \mathrm{mL}$ heparin. Then, the tissues were homogenized in 5-10 mL cold buffer (around $50 \mathrm{mM}$ potassium phosphate $\mathrm{pH} 7.5,1 \mathrm{mM}$ EDTA) per gram tissue utilizing tissue homogenizer. At that point the samples were centrifuged at $5000 \mathrm{rpm}$ for $15 \mathrm{~min}$ at $4{ }^{\circ} \mathrm{C}$. The supernatant were evacuated for examine and put away on ice.

\section{Kidney Functions Biomarkers and Electrolytes}

Urea levels were measured according to technique depending on oxidation of two moles of NADH into $\mathrm{NAD}+$ for each mole of urea hydrolyzed using urease (EC 3.5.1.5) and glutamate dehydrogenase (EC 1.4.1.2) (Sampson et al., 1980). Creatinine concentration was detected by kinetic colorimetric assay depending on formation of a yellow-orange complex by creatinine in alkaline solution. The rate of dye formation was proportional to creatinine concentration in the specimen (Toora, 2002). All the biochemical analysis of kidney function was detected using commercial kit (Diamond, Egypt) according to Roche/Hitachi Cobas c systems. The levels of serum electrolytes (Potassium, sodium and calcium ions) using commercial kits (Sensa core electrolyte, India).

\section{Oxidative Stress Biomarkers}

Determination of reduced Glutathione (GSH) was colorimetrically determined using the kit of BioDiagnostic, Egypt (CAT. No GR 2511) relying on conversion of 5,5'-dithiobis-2-nitrobenzoic acid (DTNB) into 5'-Thionitrobenzoate (TNB) and the yellow colored precipitate is detected at $412 \mathrm{~nm}$ (Beutler, 1963). The lipid peroxide (Malondialdehyde, MDA) was detected depending on its reaction with Thiobarbituric Acid (TBA) at $95^{\circ} \mathrm{C}$ for $30 \mathrm{~min}$ in acidic medium to give pink product which can be evaluated at $534 \mathrm{~nm}$ (Ohkawa et al., 1979). Super Oxides Dismutase enzyme (SOD) (EC 1.15.1.1) assessment was done using the commercial kit (Biodiagnostic kit, Egypt, CAT. No \# SD2521) depending on the ability of enzyme to inhibit the reduction of nitro-blue terazosin dye by phenazine methosulfate. At $25^{\circ} \mathrm{C}$ the absorbance determined at $560 \mathrm{~nm}$ for both control and sample (Nishikimi, 1975). Catalase enzyme (EC 1.11.1.6) was estimated by colorimetric method following the instruction of Biodiagnostic kit, Egypt (CAT. No \# SD2517). The measuring of the end product (quinoneimine dye) was determined at $510 \mathrm{~nm}$. The density colored product quinoneimine dye is due to the interaction between the catalase and standard amount of $\mathrm{H}_{2} \mathrm{O}_{2}$ (Saggu et al., 2014).

\section{Histopathological and Immunohistochemical Detection of p53 and TNF $\alpha$ Expression}

Fixed kidney in $10 \%$ neutral buffered formalin from different groups were stained using routine haematoxylin and eosin counterstain methods (Tousson, 2016). 
The changes in the immunoreactivities of apoptotic p53 proteins and cytokines tumor necrosis factor- $\alpha$ (TNF- $\alpha)$ in kidney sections were detected using Avidin Biotin Complex (ABC) (Elite-ABC, Vector Laboratories, CA, USA). Sections were incubated with anti-rabbit p53 antibody (dilution 1:80; DAKO Japan Co, Ltd, Tokyo, Japan) according to Tousson et al. (2014). Sections were incubated with anti-rabbit TNF $\alpha$ antibody (dilution 1:200; DAKO Japan Co, Ltd, Tokyo, Japan) according to Altwaijry et al. (2020).

\section{Statistical Analysis}

Al the obtained data were statistically analyzed using the Statistical Package for the Social Sciences (SPSS software version 16). Data were expressed as mean \pm Standard Error of Mean (SEM). One-way ANOVA (Analysis of Variances) followed by Dennett test were performed to evaluate the significance of differences between groups. The criterion of the statistical significance was set at $\mathrm{p}<0.05$.

\section{Results}

Characterization of $\mathrm{Fe}_{3} \mathrm{O}_{4} / \mathrm{Ag}$ Core-Shell Nanoparticles (SEM Analysis, XRD Analysis and Magnetic Analysis)

The scanning electron micrograph (Fig. 1) shows more compact and better separated particles and the aggregates with size of $33.66 \mathrm{~nm}$. Clearly, the SEM data serve as an important piece of evidence for the formation of $\mathrm{Fe}_{3} \mathrm{O}_{4} / \mathrm{Ag}$ core-shell nanoparticles.

The phase identification and crystalline structures of the nanoparticles was characterized by X-ray powder diffraction (Table 1 and Fig 2).
Magnetic properties of $\mathrm{Fe}_{3} \mathrm{O}_{4}-\mathrm{Ag}$ composite were studied with a magnetometer with vibrating sample (a maximum applied field of $30 \mathrm{kOe}$ ) at ambient temperature (Table 2).

\section{Kidney Functions Biomarkers and Electrolytes}

Rats injected with $\mathrm{Fe}_{3} \mathrm{O}_{4} / \mathrm{AgNPs}$ (G3) $\mathrm{Fe}_{3} \mathrm{O}_{4} / \mathrm{AgNPs}$-group) displayed significant elevation level of serum urea, creatinine, potassium ions and calcium ions. In contrast, serum sodium and calcium ions levels significantly reduced in G3 if compared to control (G1) and G2 (chicory administered group). Improvement in electrolytes and renal functions were observed after the treatment with Chicory after $\mathrm{Fe}_{3} \mathrm{O}_{4} / \mathrm{AgNPs}$ (G4) if compared with G3 (Table 3).

\section{Oxidative Stress Biomarkers}

Oxidative stress parameter showed significant decrease in GSH concentrations, SOD and Catalase enzymes activities in G3 if compared to G1 and G2. However, MDA concentrations significantly increased in G3 compared with G1 and G2. By chicory treatment, there were ameliorations in all oxidative parameter (GSH, SOD, Catalase and MDA) in comparison with G3 (Table 4).

\section{Kidney Histopathology}

Kidney sections in the control and chicory groups showed normal histological structures of the glomeruli and tubules in the cortical and medullary portions (Fig. 4A and 4B). Kidney section in G3 showed severe atrophy of tubular cells and glomeruli, necrotic tubular cells and mild inflammatory cellular infiltration (Fig 4C). On the other hand, G4 exhibited a good degree of improvement in the glomeruli and renal tubules (Fig 4D).

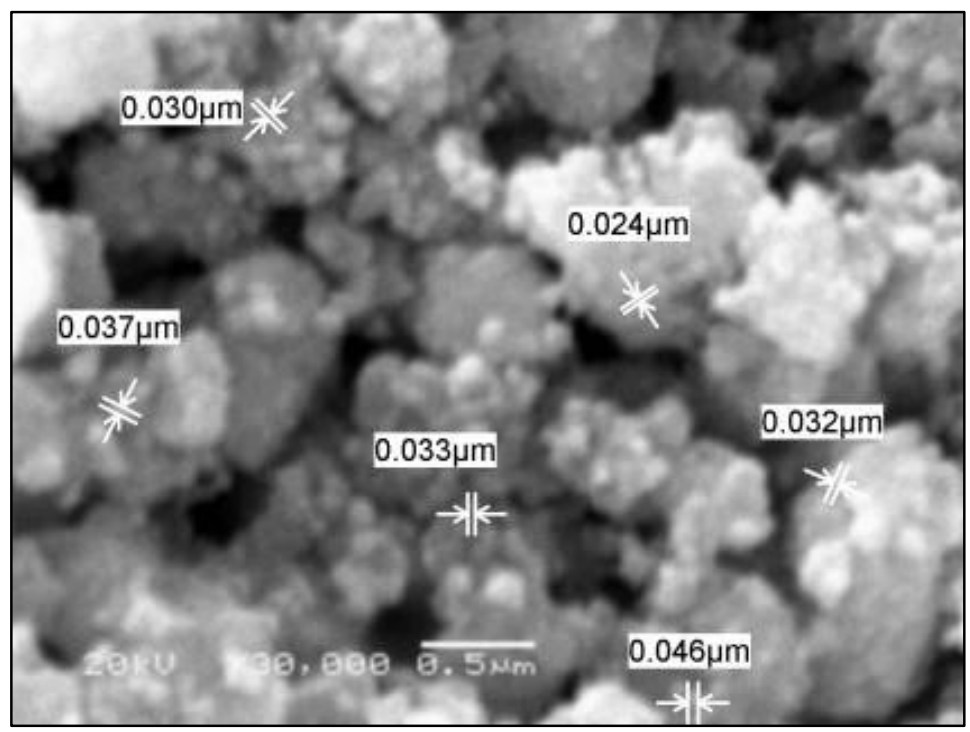

Fig. 1: SEM micrograph of $\mathrm{Fe}_{3} \mathrm{O}_{4} / \mathrm{AgNPs}$ 


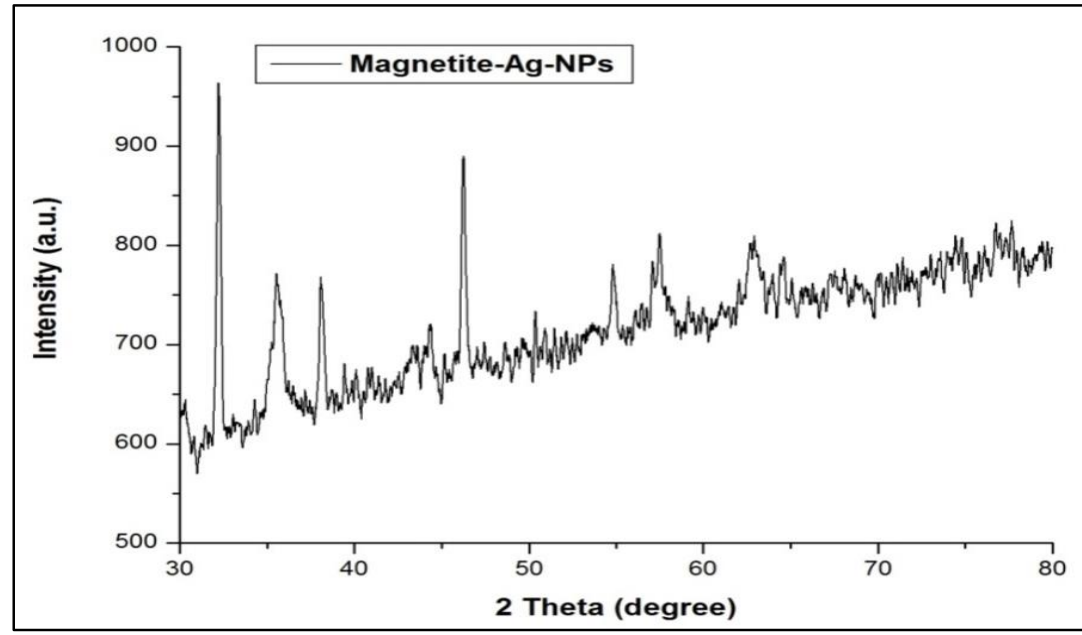

Fig. 2: X-ray diffraction pattern of the prepared $\mathrm{Fe}_{3} \mathrm{O}_{4}-\mathrm{Ag} \mathrm{NPs}$

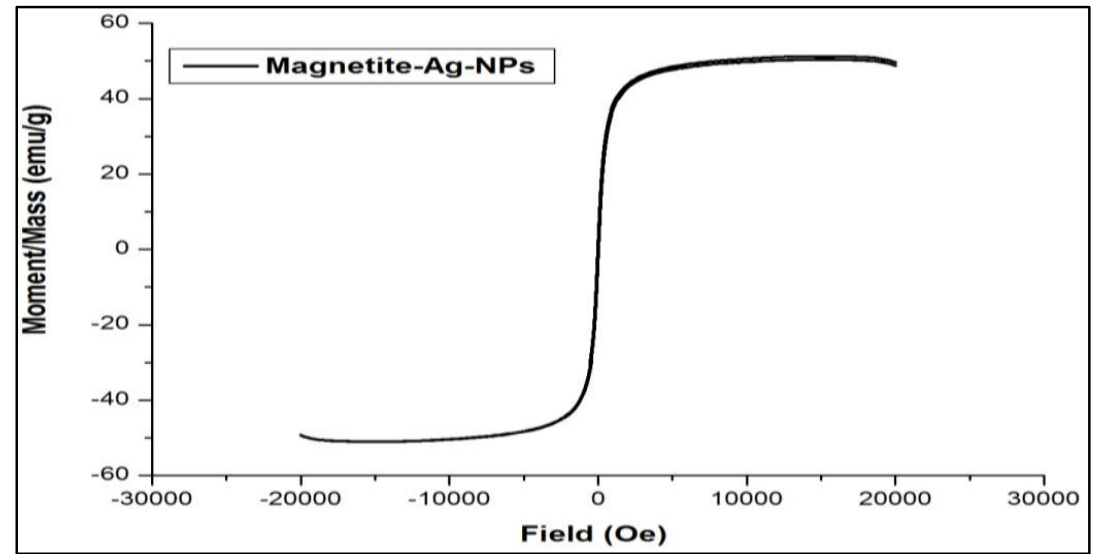

Fig. 3: The relation between the applied magnetic field (H) (Oe) and the magnetization (M) (emu/g) of $\mathrm{Fe}_{3} \mathrm{O}_{4}$ and $\mathrm{Fe}_{3} \mathrm{O}_{4}-\mathrm{Ag} \mathrm{NPs}_{\mathrm{N}}$

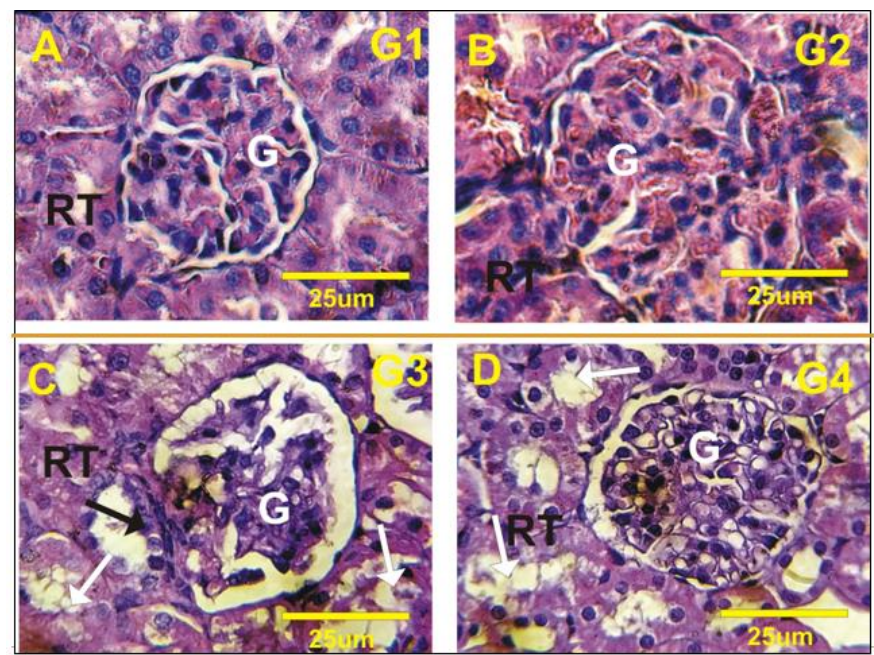

Fig. 4: Photomicrographs of kidney sections in the different experimental groups stained with Hematoxylin and Eosin. A, B: Kidney sections in the control and Chicory groups (G1 and G2) showed normal histological structures of the Glomeruli (G) and Tubules (RT). C: Kidney section of $\mathrm{Fe}_{3} \mathrm{O}_{4} / \mathrm{AgNPs}$-group (G3) showed severe atrophy in tubular cells and glomeruli, necrotic tubular cells (white arrow) and mild inflammatory cellular infiltration (Black arrows). D: Kidney section in treated rats with Chicory extract after $\mathrm{Fe}_{3} \mathrm{O}_{4} / \mathrm{AgNPs}$ injection (G4) exhibited moderate atrophy in tubular cell 


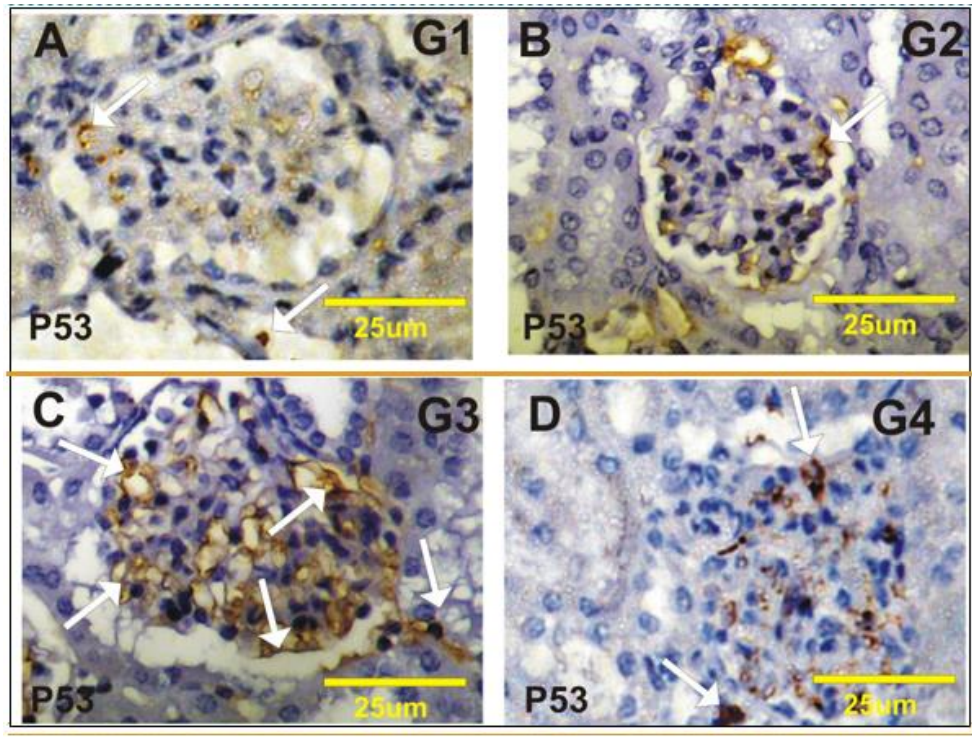

Fig. 5: Photomicrographs of kidney sections in the different experimental groups stained with P53 immunoreactivity (P53 - ir). A and B: Faint positive reaction for P53-ir (arrows) in Glomeruli $(G)$ and tubules in control (G1) and Chicory groups (G2). C: Strong positive reactions (arrows) for P53 in $\mathrm{Fe}_{3} \mathrm{O}_{4} / \mathrm{AgNPs}$-group (G3). D: Mild positive reactions (arrows) for P53 in treated rats with Chicory extract after $\mathrm{Fe}_{3} \mathrm{O}_{4} / \mathrm{AgNPs}$ injection (G4)
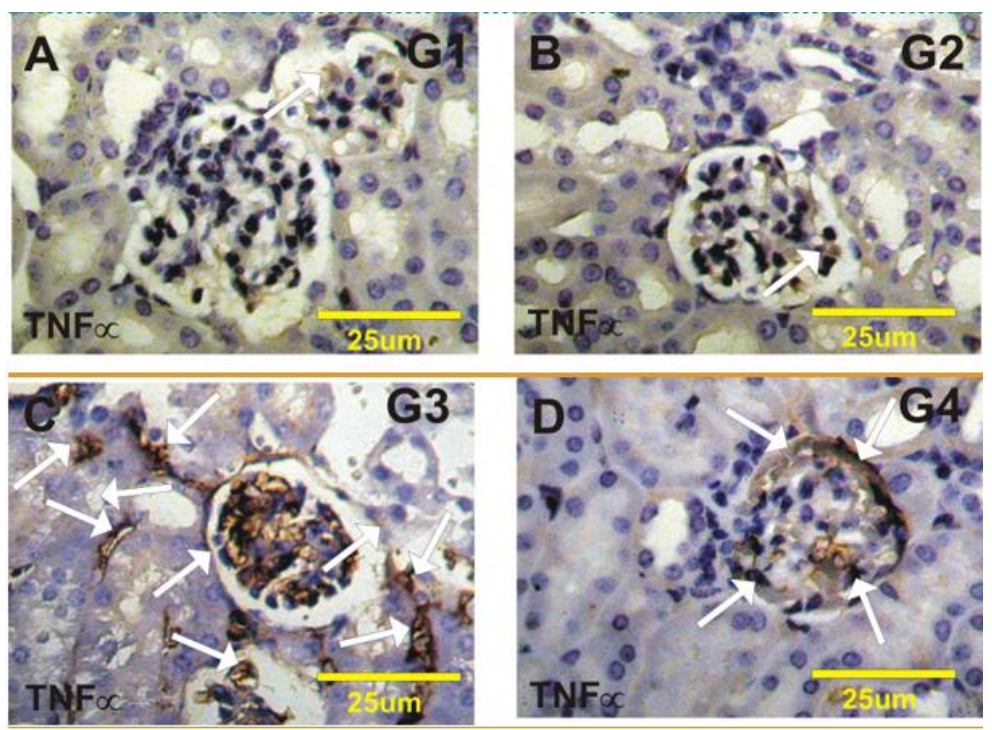

Fig. 6: Photomicrographs of kidney sections in the different experimental groups stained with TNF $\alpha$-ir. A and B: Faint positive reaction for TNF $\alpha$-ir (arrows) in Glomeruli (G) and tubules in control (G1) and Chicory groups (G2). C: Strong positive reactions (arrows) for $\mathrm{TNF} \alpha$ in $\mathrm{Fe}_{3} \mathrm{O}_{4} / \mathrm{AgNPs}$-group (G3). D: Mild positive reactions (arrows) for TNF $\alpha$ in treated rats with Chicory extract after $\mathrm{Fe}_{3} \mathrm{O}_{4} / \mathrm{AgNPs}$ injection (G4)

Table 1: Interplanar spacing and lattice parameters of $\mathrm{Fe}_{3} \mathrm{O}_{4} / \mathrm{Ag}$ NPs

\begin{tabular}{|c|c|c|c|c|c|}
\hline Diffraction angle $[2 \Theta]$ (degree) & FWHM $[\beta]$ radian & Size $[\mathrm{D}](\mathrm{nm})$ & $\mathrm{d}_{\mathrm{hkl} l}$-spacing $(\AA)$ & Diffraction planes (hkl) & Relative intensity (\%) \\
\hline [32.21] 16.11 & 0.004 & 36.09 & 2.77 & 111 & 100 \\
\hline [35.54] 17.77 & 0.006 & 24.27 & 2.52 & 200 & 38 \\
\hline [38.09] 19.05 & 0.0039 & 37.62 & 2.36 & 200 & 40 \\
\hline [46.22] 23.11 & 0.0041 & 36.77 & 1.96 & 211 & 70 \\
\hline [57.08] 28.54 & 0.0026 & 60.72 & 1.61 & 300 & 28 \\
\hline [57.45] 28.73 & 0.0043 & 36.78 & 1.60 & 300 & 30 \\
\hline [62.66] 31.33 & 0.005 & 32.74 & 1.48 & 311 & 21 \\
\hline
\end{tabular}

Average particle size [D]: (i) [37.85 nm from (XRD)]; (ii) [33.66 nm from (SEM)] Lattice constant [a] = $4.84 \AA$ 
Table 2: Magnetic properties of $\mathrm{Fe}_{3} \mathrm{O}_{4} / \mathrm{AgNPs}$

\begin{tabular}{lc}
\hline Tunable magnetic parameters & Magnetite-Ag NPs \\
\hline Coercivity (Hc, Oe) & 1.53 \\
Magnetization (Ms, emu/g) & 51.1 \\
Retentivity (Mr, emu/g) & 0.14 \\
Squareness (Sr) & $2.749 \times 10^{-3}$ \\
\hline
\end{tabular}

Table 3: Assessment of serum levels of kidney functions and electrolytes in different groups

\begin{tabular}{lllll}
\hline Parameter & $\mathrm{G} 1$ & $\mathrm{G} 2$ & $\mathrm{G} 3$ & $\mathrm{G} 4$ \\
\hline Urea $(\mathrm{mg} / \mathrm{dl})$ & $25.7^{\mathrm{b}} \pm 0.91$ & $24.11^{\mathrm{b}} \pm 0.86$ & $40.02^{\mathrm{a}} \pm 2.06$ & $28.20^{\mathrm{a}, \mathrm{b}} \pm 1.12$ \\
Creatinine $(\mathrm{mg} / \mathrm{dl})$ & $0.52^{\mathrm{b}} \pm 0.04$ & $0.48^{\mathrm{b}} \pm 0.04$ & $0.81^{\mathrm{a}} \pm 0.03$ & $0.55^{\mathrm{b}} \pm 0.04$ \\
$\mathrm{Na}^{+}(\mathrm{mEq} / \mathrm{l})$ & $148.5^{\mathrm{b}} \pm 2.08$ & $148.2^{\mathrm{b}} \pm 3.25$ & $135.6^{\mathrm{a}} \pm 1.40$ & $140.2^{\mathrm{a}, \mathrm{b}} \pm 1.38$ \\
$\mathrm{~K}^{+}(\mathrm{mEq} / \mathrm{l})$ & $3.98^{\mathrm{b}} \pm 0.16$ & $3.88^{\mathrm{b}} \pm 0.19$ & $4.89^{\mathrm{a}} \pm 0.12$ & $4.26^{\mathrm{a}, \mathrm{b}} \pm 0.25$ \\
$\mathrm{Ca}^{++}(\mathrm{mEq} / \mathrm{l})$ & $1.155 \pm 0.08$ & $1.189 \pm 0.10$ & $0.962 \pm 0.09$ & $1.123 \pm 0.09$ \\
\hline
\end{tabular}

Data are presented as mean \pm SEM, $n=10$ per group. a: Significant vs. control group (G1) at $\mathrm{p}<0.05$, b: Significant vs. $\mathrm{Fe}_{3} \mathrm{O}_{4} / \mathrm{AgNPs}^{-}$ group (G3) at $\mathrm{p} \leq 0.05$

Table 4: Assessment of oxidative stress parameters in different groups

\begin{tabular}{lllll}
\hline Parameter & G1 & G2 & G3 & G4 \\
\hline GSH $(\mu$ mol/g. tissue) & $5.32^{\mathrm{b}} \pm 0.34$ & $5.41^{\mathrm{b}} \pm 0.52$ & $3.18^{\mathrm{a}} \pm 0.70$ & $4.98^{\mathrm{b}} \pm 0.21$ \\
SOD $(\mathrm{U} / \mathrm{mg}$ protein) & $55.56^{\mathrm{b}} \pm 0.92$ & $58.02^{\mathrm{b}} \pm 1.12$ & $41.20^{\mathrm{a}} \pm 0.78$ & $49.41^{\mathrm{a}, \mathrm{b}} \pm 2.05$ \\
Catalase (U/mg protein) & $47.62^{\mathrm{b}} \pm 0.67$ & $48.22^{\mathrm{b}} \pm 2.50$ & $33.75^{\mathrm{a}} \pm 1.14$ & $42.88^{\mathrm{a}, \mathrm{b}} \pm 0.83$ \\
MDA $(\mu \mathrm{mol} / \mathrm{g}$. tissue) & $0.83^{\mathrm{b}} \pm 0.12$ & $0.80^{\mathrm{b}} \pm 0.24$ & $1.75^{\mathrm{a}} \pm 0.37$ & $1.16^{\mathrm{b}} \pm 0.28$ \\
\hline
\end{tabular}

Data are presented as mean \pm SEM, $n=10$ per group. a: Significant vs. control group (G1) at $\mathrm{p}<0.05$, b: Significant vs. $\mathrm{Fe}_{3} \mathrm{O}_{4} / \mathrm{AgNPs}^{-}$ group (G3) at $\mathrm{p} \leq 0.05$

\section{Immunohistochemical Changes of Apoptotic p53 Protein and TNFa Expressions in Kidney}

Detection of p53 and TNF $\alpha$ expressions in kidney sections of G3 showed strong positive reaction for p53 and TNF $\alpha$ expression as compared to the expression in G1 and $\mathrm{G} 2$ groups which showed faint positive expression for the both (Fig. 5A-2C and 6A-6C, respectively).

On the other hand; mild positive expression for $\mathrm{p} 53$ and TNFawere detected in kidney sections of treated rats withFe $\mathrm{O}_{4} / \mathrm{AgNPs}$ and Chicory extract (Fig. 5D and $6 \mathrm{D}$, respectively).

\section{Discussion}

XRD peaks characteristic for the $\mathrm{Fe}_{3} \mathrm{O}_{4}$ phase are observed in our previously prepared magnetite nanoparticles without adding silver metal (Abdo et al., 2019). Additional peaks, at angular positions $32.21^{\circ}(111), 38.09^{\circ}(200), 46.22^{\circ}$ (211) and $57.45^{\circ}(300)$, are attributed to metallic silver. This is a proof that silver salt was reduced to metal and successfully introduced into the iron oxide substrate.

The average crystal size of $\mathrm{Fe}_{3} \mathrm{O}_{4}-\mathrm{Ag}$ NPs was about $37.85 \mathrm{~nm}$ after the $\mathrm{Fe}_{3} \mathrm{O}_{4}$ nanoparticles were coated with silver. Furthermore, the most intensive peak located at $2 \theta=32.21^{\circ}$ corresponding to the diffractions of nanoparticles crystallized in the FCC structure with basal (111) lattice plane. The results were somewhat in good agreement with the data obtained from the SEM image (Fig. 1). Thus, both XRD and SEM provide strong evidence that the $\mathrm{Fe}_{3} \mathrm{O}_{4}-\mathrm{Ag}$ composite magnetic nanoparticles have a core-shell structure.
Magnetic saturation (Ms) of $\mathrm{Fe}_{3} \mathrm{O}_{4}-\mathrm{Ag}$ nanoparticles has shown some changes in field-dependent magnetization after the incorporation of a silver shell as compared with our previously prepared magnetite nanoparticles (Abdo et al., 2019). There was a decrease in the saturation Magnetization (Ms) from 57.4 to $51.1 \mathrm{emu} / \mathrm{g}$, decrease in the remnant Magnetization (Mr) from 0.39 to $0.14 \mathrm{emu} / \mathrm{g}$ and a decrease in coercivity $(\mathrm{Hc})$ from 4.21 to $1.53 \mathrm{Oe}$. Additional coverage with silver weakens magnetization intensity further, which diminishes Magnetic remanence value (Mr) for the $\mathrm{Fe}_{3} \mathrm{O}_{4}-\mathrm{Ag}$ nanostructures.

The obtained results in this study indicated that $\mathrm{Fe}_{3} \mathrm{O}_{4} / \mathrm{AgNPs}$ administration in rats (G3) causes renal destruction and elevation of both urea and creatinine concentrations by about 1.5 folds compared to control Group (G1). Elevation was due to severe atrophy in tubular cells and glomeruli, necrotic tubular cells and mild inflammatory cellular infiltration as confirmed by histological result. These results were in line with previous studies (Vasanth and Kurian, 2017).

The important functions of kidney are the precision of the body fluids, electrolytes and acid-base balance. In Chronic Kidney Disease (CKD) prognosticate outcome multiple disturbance including hyperkalemia, metabolic acidosis and hyperphosphatemia (Dhondup and Qian, 2017). Assessment of electrolytes showed that the concentrations of $\mathrm{K}^{+}$significantly increased in G3 (rats injected with $\mathrm{Fe}_{3} \mathrm{O}_{4} / \mathrm{AgNPs}$ ) by about 1.2 folds if compared to G1 (control). This increase was due to kidney injury. On the other hand, $\mathrm{Na}^{+}$and $\mathrm{Ca}^{+2}$ concentrations significantly decreased in G3 in comparison with G1 by 0.9 and 0.8 folds, respectively. Hyperkalemia and 
hyponatremia are common features of chronic renal failure. This can be explained by low and passive back diffusion through damaged tubular cells. Decrease in Glomerular Filtration Rate (GFR), tubular flow and reabsorption dysfunction, also tissue injury and acute $\mathrm{K}^{+}$ load are occurred (Singh et al., 2017; Kovesdy, 2014). CKD caused marked disruption in bone and mineral metabolism which in turn resulted in decreased serum calcium (Gallant and Spiegel, 2017).

The study of oxidative biomarker showed that induction of $\mathrm{Fe}_{3} \mathrm{O}_{4} / \mathrm{AgNPs}$ in $\mathrm{G} 3$ caused redundant damage in kidney by increasing the concentration of MDA by about 1.86 fold compared to its normal concentrations in G1. However, GSH concentrations SOD and catalase enzyme activities decreased by about $0.71-0.74$ folds in comparison with their normal values in G1. It has been demonstrated by a number of in vivo studies that AgNPs induce cytotoxicity and DNA damage in the kidney. The mechanism of cytotoxicity related to oxidation of AgNPs which causes $\mathrm{H}_{2} \mathrm{O}_{2}$ releasing. Reactive Oxygen Species (ROS) generation in the kidney have a significant role in the AKI genesis. ROS related to renal injury including superoxide ions, hydrogen peroxide and hydroxyl radicals cause decreasing in antioxidant enzyme status in both blood and tissue (Barbir et al., 2019; Shrivastava et al., 2016).

$\mathrm{TNF} \alpha$ is a proinflammatory cytokine. It can be considered as antitumorigenic agent that is mainly synthesized by immune cells as macrophages and lymphocytes. Additionally, several studies indicated that TNF $\alpha$ originated inside the kidney in podocytes, mesangial cells and epithelial cells from proximal tubules, thick ascending limbs and collecting ducts. TNF $\alpha$ concentration increases in different injuries as renal failure, glomerulonephritis, diabetic nephropathy and interstitial tubular nephritis. Our result showed high expression of $\mathrm{TNF} \alpha$ in the both glomeruli and tubules. The high expression of $\mathrm{TNF} \alpha$ was demonstrated in $\mathrm{G} 3$ which administrated by $\mathrm{Fe}_{3} \mathrm{O}_{4} / \mathrm{AgNPs}$ compared with normal rats in G1. That was because that oxidative stress caused by $\mathrm{Fe}_{3} \mathrm{O}_{4} / \mathrm{AgNPs}$ enhances TNF $\alpha$ production. This stimuli cause migration of dendritic cell, macrophage and lymphocyte to the kidney. This migration enhanced expression of endothelial adhesion molecules and chemokines by the kidney in response to elevations in renal derived TNF $\alpha$ (Ramseyer and Garvin, 2013; Sonkar and Singh, 2009).

The result also showed high expression of p53 in kidney tissues in rats of G3 compared to G1. This elevation confirmed that $\mathrm{Fe}_{3} \mathrm{O}_{4} / \mathrm{AgNPs}$ causes DNA destruction, which can lead to activation of p53-dependent signalling pathway. Activation of p53 intercede cell cycle arrest and activated the apoptotic pathway and lead to cellular failure such as oxidative stress, hypoxia, heat shock and activation of oncogenes (Kovács et al., 2016).
Treatment of rats by chicory extract in G4 showed excellent regression to nearly normal values in all studied parameters as urea, creatinine, electrolytes and oxidative stress markers. Even histological studies and immunohistochemical staining ( $\mathrm{p} 53$ and $\mathrm{TNF} \alpha$ ) showed good recovery from the toxic effect of $\mathrm{Fe}_{3} \mathrm{O}_{4} / \mathrm{AgNPs}$ administration after chicory extract treatment. It can be discussed in consideration with the fact that chicory extract contains different chemical compound such as inulin, coumarins, flavonoids, sesquiterpene lactones (lactenin and lactucopicrin), tannins, alkaloids, vitamins, minerals and volatile oils. These chemical compounds especially flavonoid, tannins and coumarins have several antioxidant, antitumor, anti- inflammatory activities (Nwafor et al., 2017).

\section{Conclusion}

This study assessed the protective effect of hydro-alcoholic extract of Chicory fruits (Cichorium intybus) administration against renal toxic effects produced due to chronic exposure of $\mathrm{Fe} 3 \mathrm{O} 4 / \mathrm{AgNPs}$. $\mathrm{Fe}_{3} \mathrm{O}_{4} / \mathrm{AgNPs}$ were synthesized as core-shell nanoparticles by a co-precipitation method. $\mathrm{Fe}_{3} \mathrm{O}_{4} / \mathrm{AgNPs}$ were characterized by XRD, SEM and VSM. SEM showed core-shell nanoparticles with size of $33.66 \mathrm{~nm}$, which somewhat in a good agreement with the data obtained from XRD. Magnetic measurement revealed the superparamagnetic nature of the synthesized $\mathrm{Fe}_{3} \mathrm{O}_{4} / \mathrm{AgNPs}$. The obtained results indicated that chicory extract can enhance renal activity and recover kidney injury and oxidative stress induced by $\mathrm{Fe}_{3} \mathrm{O}_{4} / \mathrm{AgNPs}$.

\section{Acknowledgement}

This study is supported by the Biochemistry division, Faculty of Science, Damanhur University where all the biochemical markers were assessed. The animal experiment was carried out in the animal house of Faculty of Science, Tanta University.

\section{Author's Contribution}

Doha M. Beltagy: The experiment idea with performing the biochemical analysis with its interpretation and the manuscript writing and revision.

Ehab Tousson: Histological and immunochemical analysis.

Nabiha I Abdo: Synthesis of nanoparticles and its analysis.

Batoul M. Izzularab: biochemical and statistical analysis with its interpretation with writing the draft of the manuscript.

\section{Ethics}

All the authors declared that this article is original with no any ethical conflict of interest. 


\section{References}

Abdo, N. I., Abobakr, S. M., Abd El-Wahab, A. E., \& El-Deeb, N. M. (2019). Superparamagnetic iron oxide nanoparticles with antimicrobial activities: synthesis and characterization of stable dispersion of $\mathrm{Fe}_{3} \mathrm{O}_{4}$ in DMSO/citric acid. Advanced Science, Engineering and Medicine, 11(8), 783-788. https://doi.org/10.1016/j.ijpharm.2009.01.009

Altwaijry, N., El-Masry, T. A., Alotaibi, B. S., Tousson, E., Alodhayani, A. A., El-Morshedy, K. \& Saleh, A. (2021). Potential therapeutic effects of avenanthramide-C against lung toxicity caused by silver nanoparticles injection in rats. Pak J Pharm Sci, 34(1), 337-343.

https://europepmc.org/article/med/34275859.

Altwaijry, N., El-Masry, T. A., Alotaibi, B., Tousson, E., \& Saleh, A. (2020). Therapeutic effects of rocket seeds (Eruca sativa L.) against testicular toxicity and oxidative stress caused by silver nanoparticles injection in rats. Environmental Toxicology, 35(9), 952-960. doi.org/10.1002/tox.22931

Barbir, R., Goessler, W., Ćurlin, M., Micek, V., Milić, M., Vuković, B. \& Vinković Vrček, I. (2019). Protein corona modulates distribution and toxicological effects of silver nanoparticles in vivo. Particle \& Particle Systems Characterization, 36(8), 1900174. doi.org/10.1002/ppsc.201900174

Basile, D. P. anderson, M. D., \& Sutton, T. A. (2012). Pathophysiology of acute kidney injury. Comprehensive Physiology, 2(2), 1303. doi.org/10.1002/cphy.c110041

Beutler, E. (1963). Improved method for the determination of blood glutathione. J. lab. clin. Med., 61, 882-888. https://pubmed.ncbi.nlm.nih.gov/13967893/

Dhondup, T., \& Qian, Q. (2017). Electrolyte and acid-base disorders in chronic kidney disease and end-stage kidney failure. Blood purification, 43(1-3), 179-188. doi.org/10.1159/000452725

Gallant, K. M. H., \& Spiegel, D. M. (2017). Calcium balance in chronic kidney disease. Current Osteoporosis Reports, 15(3), 214-221.

https://pubmed.ncbi.nlm.nih.gov/28474258/

Hassan, H. A., \& Yousef, M. I. (2010). Ameliorating effect of chicory (Cichorium intybus L.) -supplemented diet against nitrosamine precursorsinduced liver injury and oxidative stress in male rats. Food and Chemical Toxicology, 48(8-9), 2163-2169. doi.org/10.1016/j.fct.2010.05.023

Hassanen, E. I., Khalaf, A. A., Tohamy, A. F., Mohammed, E. R., \& Farroh, K. Y. (2019). Toxicopathological and immunological studies on different concentrations of chitosan-coated silver nanoparticles in rats. International journal of nanomedicine, 14, 4723. doi.org/10.2147/IJN.S207644
Hosu, O., Tertis, M., \& Cristea, C. (2019). Implication of magnetic nanoparticles in cancer detection, screening and treatment. Magnetochemistry, 5(4), 55. https://www.mdpi.com/2312-7481/5/4/55

Ivashchenko, O., Lewandowski, M., Peplińska, B., Jarek, M., Nowaczyk, G., Wiesner, M. \& Jurga, S. (2015). Synthesis and characterization of magnetite/silver/antibiotic nanocomposites for targeted antimicrobial therapy. Materials Science and Engineering: C, 55, 343-359. doi.org/10.1016/j.msec.2015.05.023

Keshk, W. A., Soliman, N. A., Ali, D. A., \& Elseady, W. S. (2019). Mechanistic evaluation of AMPK/SIRT1/FXR signaling axis, inflammation and redox status in thioacetamide-induced liver cirrhosis: The role of Cichorium intybus linn (chicory)-supplemented diet. Journal of Food Biochemistry, 43(8), e12938. https://pubmed.ncbi.nlm.nih.gov/31368578/

Kovács, D., Igaz, N., Keskeny, C., Bélteky, P., Tóth, T., Gáspár, R. \& Kiricsi, M. (2016). Silver nanoparticles defeat p53-positive and p53-negative osteosarcoma cells by triggering mitochondrial stress and apoptosis. Scientific Reports, 6(1), 1-13. https://pubmed.ncbi.nlm.nih.gov/27291325/

Kovesdy, C. P. (2014). Management of hyperkalaemia in chronic kidney disease. Nature Reviews Nephrology, 10(11), 653. doi.org/10.1038/nrneph.2014.168

Malapati, V., Venkataratnam, K. K., \& Singh, R. (2018, April). Structure and magnetic properties of $\mathrm{Mn}-\mathrm{Fe}$ co-doped $\mathrm{ZnO}$ thin films deposited by RFmagnetron sputtering. In AIP Conference Proceedings (Vol. 1942, No. 1, p. 080055). AIP Publishing LLC. doi.org/10.1063/1.5028889

Mutar, T. F., Tousson, E., Hafez, E., Abo Gazia, M., \& Salem, S. B. (2020). Ameliorative effects of vitamin B17 on the kidney against Ehrlich ascites carcinoma induced renal toxicity in mice. Environmental Toxicology, 35(4), 528-537. doi.org/ 10.1002/tox.22888

Nishikimi, M. (1975). Oxidation of ascorbic acid with superoxide anion generated by the xanthine-xanthine oxidase system. Biochemical and biophysical research communications, 63(2), 463-468. doi.org/ 10.1016/0006-291x(75)90710-х

Nwafor, I. C., Shale, K., \& Achilonu, M. C. (2017). Chemical composition and nutritive benefits of chicory (Cichorium intybus) as an ideal complementary and/or alternative livestock feed supplement. The Scientific World Journal, 2017. doi.org/10.1155/2017/7343928

Ohkawa, H., Ohishi, N., \& Yagi, K. (1979). Assay for lipid peroxides in animal tissues by thiobarbituric acid reaction. Analytical biochemistry, 95(2), 351-358. doi.org/ 10.1016/0003-2697(79)90738-3

Ramseyer, V.D. \& Garvin, J.L. (2013). Tumor necrosis factor- $\alpha$ : regulation of renal function and blood pressure. Am. J. Physiol. Renal Physiol. 15;304(10): 1231-1242. doi.org/10.1152/ajprenal.00557.2012. 
Saggu, S., Sakeran, M. I., Zidan, N., Tousson, E., Mohan, A., \& Rehman, H. (2014). Ameliorating effect of chicory (Chichorium intybus L.) fruit extract against 4-tert-octylphenol induced liver injury and oxidative stress in male rats. Food and chemical toxicology, 72, 138-146. doi.org/10.1016/j.fct.2014.06.029

Sampson, E. J., Baird, M. A., Burtis, C. A., Smith, E. M., Witte, D. L., \& Bayse, D. D. (1980). coupled-enzyme equilibrium method for measuring urea in serum: optimization and evaluation of the AACC study group on urea candidate reference method. Clinical Chemistry, 26(7), 816-826.

https://pubmed.ncbi.nlm.nih.gov/7379302/

Shrivastava, R., Kushwaha, P., Bhutia, Y. C., \& Flora, S. J. S. (2016). Oxidative stress following exposure to silver and gold nanoparticles in mice. Toxicology and industrial health, 32(8), 1391-1404. doi.org/10.1177/0748233714562623

Singh, P., Deshwali, S., Potey, G. G., \& Sharma, A. (2017). Study of serum sodium and serum potassium level in chronic renal failure. Int. J. Adv. Res. Biol. Sci, 4(11), 103-111. doi.org/10.22192/ijarbs

Sonkar, G. K., \& Singh, R. G. (2009). valuation of serum tumor necrosis factor $\alpha$ and its correlation with histology in chronic kidney disease, stable renal transplant and rejection cases. Saudi Journal of Kidney Diseases and Transplantation, 20(6), 1000. doi.org/10.1152/ajprenal.00557.2012

Toora, B. D., \& Rajagopal, G. (2002). Measurement of creatinine by Jaffe's reaction-determination of concentration of sodium hydroxide required for maximum color development in standard, urine and protein free filtrate of serum.

https://pubmed.ncbi.nlm.nih.gov/12635710/
Tousson, E. (2016). Histopathological alterations after a growth promoter boldenone injection in rabbits. Toxicology and industrial health, 32(2), 299-305. doi.org/ 10.1177/0748233713500821

Tousson, E., Bayomy, M. F., \& Ahmed, A. A. (2018). Rosemary extract modulates fertility potential, DNA fragmentation, injury, KI67 and P53 alterations induced by etoposide in rat testes. Biomedicine \& Pharmacotherapy, 98, 769-774. doi.org/ 10.1016/j.biopha.2018.01.025

Tousson, E., Hafez, E., Zaki, S., \& Gad, A. (2014). P53, Bcl2 and CD68 expression in response to amethopterininduced lung injury and ameliorating role of 1-carnitine. Biomedicine \& Pharmacotherapy, 68(5), 631-639 doi.org/ 10.1016/j.biopha.2014.05.007

Tousson, E., Hafez, E., Zaki, S., \& Gad, A. (2016). The cardioprotective effects of L-carnitine on rat cardiac injury, apoptosis and oxidative stress caused by amethopterin. Environmental Science and Pollution Research, 23(20), 20600-20608. https://pubmed.ncbi.nlm.nih.gov/27464663/

Vasanth, S. B., \& Kurian, G. A. (2017). Toxicity evaluation of silver nanoparticles synthesized by chemical and green route in different experimental models. Artificial cells, nanomedicine and Biotechnology, 45(8), 1721-1727. doi.org/10.1080/21691401.2017.1282500

Yousef, M. I., Mutar, T. F., \& Kamel, M. A. E. N. (2019). Hepato-renal toxicity of oral sub-chronic exposure to aluminum oxide and/or zinc oxide nanoparticles in rats. Toxicology reports, 6, 336-346. doi.org/10.1016/j.toxrep.2019.04.003 